\title{
Proper bile duct flow, rather than radical excision, is the most critical factor determining treatment outcomes of bile duct cysts
}

Hong-Tian Xia ${ }^{*}$, Tao Yang ${ }^{\dagger}$, Yang Liu, Bin Liang, Jing Wang and Jia-Hong Dong

\begin{abstract}
Background: The purpose of this study was to compare the impact of the extent of excision and the patent bile duct flow on treatment outcomes of bile duct cysts (BDCs).

Methods: We retrospectively analyzed the records of 382 patients who received surgery for BDCs from January 2005 to December 2014.

Results: For Type la cysts, proper bile flow was associated with good long-term treatment outcomes with a greater level of significance $(p<0.001)$ than complete excision $(p=0.012)$. For Type IVa cysts, proper bile flow, but not complete excision, was associated with good long-term outcomes $(p<0.00001)$. In addition, $96.3 \%(104 / 108)$ of Type IVa patients with proper bile flow had no late complications and good biliary function, while no patient without patent bile flow had a good clinical outcome. For Type Ic cysts, 92 patients who received partial excisions had good outcomes when proper bile flow was restored. Regression analysis revealed that the absence of proper bile flow, in comparison to incomplete excision, is a greater risk factor for poor long-term treatment effects for Type la and Type IVa cysts.
\end{abstract}

Conclusions: Compared to complete excision, the establishment of proper bile flow exerted a greater impact on improving long-term clinical outcomes after BDC surgery.

Keywords: Bile duct cyst, Biliary-enteric flow, Biliary reconstruction, Biliary flow reestablishment, Total excision, Long-term biliary function

\section{Background}

Bile duct cyst, or choledochal cyst (CC), has been considered to be a rare disease that mostly occurs in children in western countries. However, the number of adult patients with CCs has been increasing in recent years due to improvements of noninvasive hepatobiliary imaging, with the reported incidence reaching up to $70 \%$ [1-6]. Adult CCs are particularly frequent in Asian countries, with a frequency of 1 per 5000 in China and 1 per 1000 in Japan [7-9]. Long-term postoperative complications of adult CCs can be as high as $80 \%$ $[3-6,10,11]$. Cholangiocarcinoma is also more frequent in

\footnotetext{
*Correspondence: xiahongtian115@sina.com

${ }^{+} \mathrm{Hong}$-Tian Xia and Tao Yang contributed equally to this work.

Hospital and Institute of Hepatobiliary Surgery, Chinese PLA General Hospital, Chinese PLA Medical School, Beijing 100853, China
}

adult CC patients $[4,6]$. The frequency of cholangiocarcinoma increases with age, and is approximately $0.42 \%$ in children under 18 years of age, $11.4 \%$ in adults, and $50 \%$ by the age of 50 [12-14].

Complete/radical cyst excision plus Roux-en-Y hepatojejunostomy has substantially reduced the incidence of postoperative long-term complications and cancer in patients with CCs $[10,15-18]$. As such, radical excision of CCs is considered the gold standard for the treatment of Todani Type I and Type IV CCs, and it is believed that incomplete cyst excision is associated with poorer clinical outcomes and a greater risk of malignancy $[7,19]$. We have also addressed the issue of surgical approach at our institution, and our findings support the effectiveness of complete excision in reducing the rate of complications and cancer [8, 15].

(c) The Author(s). 2018 Open Access This article is distributed under the terms of the Creative Commons Attribution 4.0 International License (http://creativecommons.org/licenses/by/4.0/), which permits unrestricted use, distribution, and 
However, frequently there is no histological boundary between the lesion and normal bile duct, and the so-called radical excision is based solely on the morphology assessed by visual inspection during surgery. Clinically, complete excision is not always achievable, especially in patients with widespread intrahepatic cysts, as is often found with Todani Type Ic and some Type IVa cysts [20]. As such, the rate of long-term postoperative complications remains high with an overall rate of $29.7 \%$ in adults, and $68.7 \%$ in patients of Type IVa cysts $[3,6,11,21]$.

At our institution we have treated a large number of patients who were previously treated at other institutions with or without radical excisions who required re-operation. We have observed that radical excision may not be the most critical factor determining long-term postoperative outcomes. We also observed that when radical excision could not be achieved in patients with Type I and IVa cysts, good long-term postoperative outcomes could still be obtained if patent bile duct flow was established.

The purpose of this study was to retrospectively analyze 382 cases of Todani Type Ia, Ic or IVa bile duct cysts to determine the importance of patent bile duct flow in comparison to the extent of excision (complete or partial) with respect to long-term postoperative outcomes.

\section{Methods}

\section{Patients}

The study was approved by the Institutional Review Board of the Chinese PLA General Hospital. All patients provided written informed consent for all procedures performed.

We respectively reviewed the records of all adult patients with a definite diagnosis of a Todani Type Ia, Type Ic, or Type IVa bile duct cyst who had surgical resection at our hospital during the period from January 2005 to December 2014. All patients had laboratory testing including white blood cell count (WBC), alanine aminotransferase (ALT), aspartate aminotransferase (AST), alkaline phosphatase (ALP), and gamma-glutamyl transferase (GGT). The diagnosis of a Todani Type Ia, Ic, or IVa bile duct cyst was made by imaging studies that included abdominal ultrasonography, computed tomography $(\mathrm{CT})$, and magnetic resonance cholangiopancreatography (MRCP). Postoperatively the diagnosis was confirmed by histopathological examination of the surgical specimen. Patients with biliary dilatation due to bile duct obstruction or bile duct stones were excluded from the study. Patients who had a reoperation, or with a follow-up duration less than 12 months were also excluded.

\section{Surgical methods}

The surgical treatment of patients with a Todani Type Ia bile duct cyst included complete excision or partial resection (due to hilar bile duct stricture) followed by a Roux-en-Y hepaticojejunostomy. In patients with a hilar bile duct stricture, a hilar ductoplasty was performed prior to the Roux-en-Y hepaticojejunostomy. For all Type Ic cysts, the surgery for all patients was the removal of the bile duct cysts plus Roux-en-Y hepaticojejunostomy. For Type Ia cysts, all patients were undergone the removal of the bile duct cysts, plus Roux-en-Y hepaticojejunostomy and hepatic hilar angioplasty.. Complete or partial excision was determined morphologically, rather than pathologically.

For Type IVa cysts, there were two types of surgeries. Surgery I included the removal of the extrahepatic bile duct cyst, the hepatic hilar angioplasty and Roux-en-Y hepaticojejunostomy. Surgery II included all operations of Surgery I plus partial hepatectomy.

Establishment of proper bile flow was defined according to the following criteria: 1) there was no relative bile duct constriction proximal to the anastomosis of the cholangioenterostomy; 2) the diameter of the bile duct anastomosis was greater than the diameter of the proximal intrahepatic bile duct, and there was no sign of intrahepatic cholestasis after biliary enteric anastomosis; 3) the absence of an anastomotic stricture and of intrahepatic biliary dilatation confirmed by postoperative imaging; 4) postoperative serum ALT, AST, GGT, and ALP levels returned to normal.

During postoperative follow-up, local patients were evaluated at our institution. For patients from outside the city, follow-up took place at their local hospitals. If there were any abnormalities found in non-local patients, the patients were reassessed at our institution. During the first postoperative year, all patients were followed-up every 3 months and thereafter every 6 months. Beginning at 5 years after surgery, reexamination was performed annually. Reexamination included abdominal ultrasonography, CT, and MRI, as well as biochemical blood testing. The assessments performed at the local and nonlocal hospitals were the same.

Long-term surgical efficacy was based on the occurrence of long-term postoperative complications (late complications) and long-term postoperative biliary function, and was evaluated at each revisit during the full follow-up period (67.2 \pm 29.7 months). Efficacy was evaluated based on the method by Moraca et al. [22], and the criteria developed by Lillemoe et al. [23]. Four categories were included: 1) excellent, normal biochemical examination without clinical symptoms or anatomical abnormalities; 2) good, no clinical manifestations of cholangitis with only a few small bile ducts with abnormal structures, normal or close-to-normal biochemical testing results, and no need for further intervention; 3) fair, presence of mild anatomical abnormalities of the bile ducts, clinical manifestations of cholangitis with onset $<3$ times per year, and symptoms that were amenable to conservative treatment such as antibiotics; 4) poor, recurrent cholangitis and abnormal anatomical structures of the bile ducts, bile duct strictures, and stones that did not respond to conservative treatment 
and required a reoperation [21]. The categorizations were consistent with those used in previous studies [9].

Late complications (e.g., recurrent cholangitis, bile duct stones, biliary stricture, cancer) were defined as those occurring after hospital discharge, and complications were assessed throughout the course of the follow-up period.

\section{Statistical analysis}

Continuous variables were expressed as mean \pm standard deviation (SD), while categorical data were expressed as number (\%). Data were analyzed with a chi-square test or Fisher's exact test. All statistical analyses were performed using IBM SPSS version 20, with an alpha level of 0.05 . Multiple logistic regression was performed to evaluate whether the extent of resection and the establishment of patent bile duct drainage were an independent risk factor for complications.

\section{Results}

The demographic data, and preoperative clinical information of the 382 patients are presented in Table 1. The average age of the patients was $40.4 \pm 12.0$ years, and there were 298 females and 84 males.

There were 37 patients who experienced different types of complications during hospitalization. The total complication rate was $9.69 \%$ (37/382), which was $7.75 \%$ (20/258) and $13.71 \%(17 / 124)$ for type I and IVa cysts, respectively. The main recent complications and the grading are shown in the Additional file 1: Tables S2 and S3. The treatment for bile and pancreatic leakage was to ensure patent flow. Abdominal infections were treated with antibiotics, while two cases were treated with ultrasound-guided puncture and drainage. Abdominal hemorrhage was mainly treated by hepatic arterial embolization, but two cases with poor embolization was treated with open hemostasis.

Table 1 Demographic data and preoperative status

\begin{tabular}{ll}
\hline Characteristics & Data \\
\hline Age (years) & $40.4 \pm 12.0$ \\
Gender & \\
Male & $84(22)$ \\
$\quad$ Female & $298(78.0)$ \\
Follow-up duration (months) & $67.2 \pm 29.7$ \\
Todani type & \\
la & $166(57.2 \%)$ \\
IC & $92(24.1 \%)$ \\
Type IVa diffused & $76(19.9 \%)$ \\
Type IVa localized & $48(12.6 \%)$ \\
\hline Data are expressed as mean \pm standard deviation or number (percentage)
\end{tabular}

Four patients had cancer during the follow-up period of 46 to 88 months, the rate of postoperative cancer was $1 \%$. Two cases were of type Ia and two were of type IVa cysts. Three had radical resection, but none had proper bile flow (for detail, see Additional file 1: Table S4).

The association of complete/partial excisions or proper bile flow with late complications and long-term biliary function in patients with Todani Type Ia bile duct cysts is shown in Table 2. In total, proper bile flow was achieved in 150 patients (90.4\%). Consistent with previous reports, the extent of excision (complete vs. partial excision) was significantly associated with long-term postoperative clinical outcomes (aspects of late complications and biliary function) after Type Ia bile duct cyst surgery $(p=0.012)$. Patients who had a complete excision and a proper bile flow had a significantly lower rate of late complications ( $0 \%$ vs. $16.7 \%, p<0.001)$, and a significantly higher rate of excellent biliary function outcomes $(94.2 \%$ vs. $25 \%, p<0.001)$ compared to patients with partial excision and proper bile flow. These data indicate that complete excision is important for achieving good outcomes in Type Ia bile duct cyst surgery.

However, compared to complete excision, proper bile flow was associated with good long-term postoperative clinical outcomes with a greater level of significance $(p<0.001)$. While in the absence of patent bile flow, complete excision alone resulted in a high rate of late complications (85.7\%), and poor long-term postoperative biliary function (excellent + good, 14.3\%). Thus, compared to the extent of excision, the presence of patent bile flow appears to have a greater impact on the effectiveness of surgical treatment for Type Ia bile duct cysts (Table 2).

For Type IVa cysts, complete excision showed no significant association with good long-term postoperative outcomes ( $p=0.285$; Table 3$)$. Rather, a significant association was found between proper bile flow and good long-term outcomes $(p<0.00001$; Table 3$)$. Of the 108 patients with proper bile flow, 104 (96.3\%) had no late complications and had excellent or good biliary functions, while all 16 patients without proper bile flow had late complications and fair or poor biliary function. Thus, as long as proper bile flow is present, the extent of excision did not significantly influence the long-term postoperative outcomes for Type IVa cysts.

Late complications and long-term biliary function of the 92 patients with Type Ic bile duct cysts who had a partial excision and proper postoperative bile flow are shown in Table 4. Late complications occurred in only $4.3 \%$ of the patients, and long-term biliary function was satisfactory in $95.7 \%$.

Univariate regression analysis was conducted to evaluate whether incomplete excision and the lack of proper bile flow were independent risk factors for late complications. As shown in Table 5, incomplete excision was a 
Table 2 Late complications and long-term biliary function of patients with Type la bile duct cysts

\begin{tabular}{|c|c|c|c|c|c|c|}
\hline & $\begin{array}{l}\text { Complete excision+ } \\
\text { proper bile flow }(n=138)\end{array}$ & $\begin{array}{l}\text { Complete excision } \\
\text { only }(n=14)\end{array}$ & $\begin{array}{l}\text { Partial excision+ proper } \\
\text { bile flow }(n=12)\end{array}$ & $\begin{array}{l}\text { Partial excision } \\
\text { only }(n=2)\end{array}$ & $\begin{array}{l}p \text {-value (function of } \\
\text { extent of excision) }\end{array}$ & $\begin{array}{l}P \text {-value (function o } \\
\text { proper bile flow) }\end{array}$ \\
\hline $\begin{array}{l}\text { Late } \\
\text { complications }\end{array}$ & 0 & $12(85.7)$ & $2(16.7)$ & $2(100)$ & 0.012 & $<.00001$ \\
\hline $\begin{array}{l}\text { Long-term } \\
\text { biliary function }\end{array}$ & & & & & 0.012 & $<.00001$ \\
\hline Excellent & $130(94.2)$ & $1(7.1)$ & $3(25)$ & 0 & & \\
\hline Good & $8(5.8)$ & $1(7.1)$ & $7(58.3)$ & 0 & & \\
\hline Fair & 0 & $10(71.4)$ & $2(16.7)$ & 0 & & \\
\hline Poor & 0 & $2(14.4)$ & 0 & $2(100)$ & & \\
\hline
\end{tabular}

Data are expressed as number of cases (percentage)

$P$-values were calculated based on a chi-square test to compare distributions of late complications and long term biliary function on complete excision and bile flow status

significant risk factor for late complications in Type Ia of bile duct cysts patients $(p<0.01$ and 0.05 , respectively), but not in Type IVa patients $(p=0.21)$. In comparison, lack of proper bile flow tended to be a greater risk factor for late complications in both Type Ia $(p<0.0001)$ and Type IVa bile duct cyst patients $(p<0.0001)$.

The risk factor analysis for different type of surgery in patients with Type IVa cyst revealed no significant difference (Table 6).

\section{Discussion}

Long-term postoperative outcomes have remained unsatisfactory in adults patients with bile duct cysts [3-6, 21]. In China, the absence of patent bile duct drainage after bile duct cyst surgery is very common in both lower level hospitals and top level medical centers due to insufficient attention to this problem. Every year our medical center treats a great number of adult patients with bile duct cysts that require reoperation, and we have carried out more than 20 years of clinical research to improve the long-term treatment outcomes. We have published a series of reports on the topic [9, 24-26], including some that addressed the selection of surgical approaches and confirmed the importance of radical excision $[8,15]$. During the 20 years of research, we have also noticed the crucial role of patent bile flow with respect to good long-term treatment outcomes, and therefore conducted the current study to specifically compare the role of these two factors.

Our results show that for Type Ia bile duct cysts, although complete excision of the lesioned bile duct significantly reduced the incidence of late complications and improved biliary function, the presence of proper bile flow impacted these clinical outcomes with a greater level of significance. More remarkably, for Type IVa cysts, as long as proper bile flow was ensured, complete or incomplete excision made no significant difference in terms of late postoperative complications and long-term biliary function. The regression analysis showed that the absence of proper bile flow is of greater risk compared to incomplete excision for late complications with Type Ia and IVa cysts; while incomplete excision is a risk factor for late complications in only Type Ia patients. In addition, patients with partial excision of Type Ic cysts had good clinical outcomes when proper bile flow was established.

These findings indicate that proper bile flow, rather than radical excision, is the most critical factor in reducing long-term postoperative complications and improving biliary function, although radical excision still plays an important role in the treatment of Type Ia cysts. These findings are of great clinical significance in that, if practiced widely and particularly in Asian countries, the improved surgical approach would greatly reduce the

Table 3 Late complications and long-term biliary function of patients with Type IVa bile duct cysts

\begin{tabular}{|c|c|c|c|c|c|c|}
\hline & $\begin{array}{l}\text { Complete excision+ proper } \\
\text { bile flow }(n=40)\end{array}$ & $\begin{array}{l}\text { Complete excision } \\
\text { only }(n=4)\end{array}$ & $\begin{array}{l}\text { Partial excision+ proper } \\
\text { bile flow }(n=68)\end{array}$ & $\begin{array}{l}\text { Partial excision } \\
\text { only }(n=12)\end{array}$ & $\begin{array}{l}P \text {-value (function of } \\
\text { excision level) }\end{array}$ & $\begin{array}{l}P \text {-value (function of } \\
\text { bile flow) }\end{array}$ \\
\hline $\begin{array}{l}\text { Late } \\
\text { complications }\end{array}$ & $1(2.5)$ & $4(100)$ & $3(4.4)$ & $12(100)$ & 0.285 & 0.00001 \\
\hline \multicolumn{7}{|c|}{ Long-term biliary function } \\
\hline Excellent & $36(90)$ & 0 & $57(83.9)$ & 0 & 0.285 & 0.00001 \\
\hline Good & $3(7.5)$ & 0 & $8(11.8)$ & 0 & & \\
\hline Fair & $1(2.5)$ & $3(75)$ & $2(2.9)$ & $9(75)$ & & \\
\hline Poor & 0 & $1(25)$ & $1(1.4)$ & $3(25)$ & & \\
\hline
\end{tabular}

Data are expressed as number of cases (percentage)

$P$-values were calculated based on a chi-square test to compare distributions of late complications and long term biliary function on complete excision and bile flow status 
Table 4 Late complications and long-term biliary function of patients with Type Ic bile duct cysts

\begin{tabular}{lll}
\hline & $\begin{array}{l}\text { Partial excision+ proper } \\
\text { bile flow }(n=92)\end{array}$ & P-value \\
\hline Late complications & $4(4.3)$ & $\mathrm{N} / \mathrm{A}$ \\
$\begin{array}{l}\text { Long-term biliary function } \\
\text { Excellent }\end{array}$ & $\mathrm{N} / \mathrm{A}$ \\
Good & $80(87.0)$ & \\
Fair & $8(8.7)$ & \\
Poor & $4(4.3)$ & \\
\hline
\end{tabular}

rate of long-term postoperative complications, lower the incidence of reoperation, and improve the surgical outcomes of bile duct cysts.

For complicated cases such as Type Ic and Type IVa cysts, radical resection of bile duct cysts cannot be easily achieved because of the wide distribution of cysts in the bile duct (Type IVa), or because there may be a fusiform dilatation and a pancreatobiliary malunion that may continue to the intrahepatic duct (Type Ic) [27]. We have shown that there were good long-term outcomes with these cysts when there was proper bile flow. Thus, assuring proper bile flow is essential in the surgical treatment of these types of bile duct cysts.

Of special note, in the absence of proper bile flow, patients who had complete cyst excision still had high incidences of late complications $(85.7 \%$ and $100 \%$ for Type Ia and Type IVa cysts, respectively), and low rates of excellent and good long-term postoperative biliary function $(14.3 \%$ and $0 \%$ for Type Ia and Type IVa cysts, respectively). These data further emphasize the importance of patent bile duct drainage, yet complete removal of the cysts alone does not necessarily guarantee proper bile flow into the gastrointestinal tract. The anatomical variants and the characteristics of bile duct cysts may lead to difficulties during hepaticojejunostomy, and occasionally cause postoperative biliary stricture, thereby resulting in bile stasis and cholangitis [15].

The issue of patent bile flow has been addressed previously. Todani et al. reported that free bile drainage is necessary to prevent ascending cholangitis [28]. Lenriot et al. showed that a long-lasting cure for bile duct cysts in adults can be accomplished if the following three conditions are met during the operation: eradication of pancreatic reflux, a decrease of the malignancy risk by reducing the common sites of malignant transformations, and restoration of normal bile flow [21]. Our practice is basically consistent with these studies. However, we specifically stress that to ensure proper bile flow, there should be no cholestasis or relative strictures at the anastomotic stoma. This is achieved by cholangioplasty at the porta hepatis and partial hepatectomy. Moreover, our comparative analysis revealed that patent bile flow is of greater importance than the extent of excision in the long-term treatment efficacy of bile duct cysts, particularly for Type IVa cysts.

Long-term postoperative complications, particularly recurrent cholangitis and pancreatitis, are associated with postoperative cancer $[29,30]$. It is widely believed that postoperative cancer of bile duct cysts is attributable to failure of radical resection. According to this notion, postoperative carcinogenesis occurs at the remaining cystic dilatation of the lesioned bile ducts. However, the notion is questionable for the following reasons. First of all, there is no clear histological boundary between the lesioned and normal bile duct; the so-called pathological radical resection is frequently defined by eyes and therefore arbitrary [31]. Second, the pathogenesis of pre- and postoperative carcinogenesis of bile duct cysts is completely different. Preoperative cancer is the result of the abnormal confluent pancreatic juice that erodes the bile duct, while postoperative carcinogenesis is caused by recurrent cholangitis due to obstructed bile flow [32, 33]. Postoperatively, the cause of preoperative cancer no longer exists because the biliary and pancreatic drainage are now separated, so erosion of the bile duct by pancreatic juice no longer exists. In other words, after surgery the mechanism of carcinogenesis has changed. Third, the high incidence of postoperative cancer after incomplete resection should be attributable to the failure to establish patent bile flow. As proper bile flow is easier to achieve in patients who had radical resection, the lower cancer rate may not be the result of complete resection.

In our data, there were only 4 cases of postoperative cancer during the follow-up period. All 4 patients did not have a proper bile flow, even though 3 had radical

Table 5 Risk factor analysis of late complications on the two factors: incomplete excision and lack of proper bile flow (univariate regression analysis)

\begin{tabular}{|c|c|c|c|c|c|c|c|c|c|}
\hline \multirow[b]{3}{*}{ Type } & \multirow[b]{3}{*}{ la } & \multicolumn{4}{|c|}{ incomplete excision } & \multicolumn{4}{|c|}{ Lack of proper bile flow } \\
\hline & & \multirow{2}{*}{$\frac{\text { Risk ratio }}{3.62}$} & \multicolumn{2}{|c|}{ 95\% confidence limits } & \multirow{2}{*}{$\begin{array}{l}P \text {-value } \\
0.032\end{array}$} & \multirow{2}{*}{$\begin{array}{c}\text { Risk ratio } \\
65.63\end{array}$} & \multicolumn{2}{|c|}{ 95\% confidence limits } & \multirow{2}{*}{$\frac{P \text {-value }}{<0.0001}$} \\
\hline & & & 1.34 & 9.74 & & & 16.36 & 263.23 & \\
\hline & IC & & & & & & & & \\
\hline & Iva & 1.65 & 0.64 & 4.24 & 0.21 & 27 & 10.32 & 70.63 & $<0.0001$ \\
\hline \multicolumn{2}{|l|}{ Total } & 2.33 & 1.27 & 4.27 & 0.006 & 40.3 & 18.19 & 89.35 & $<0.0001$ \\
\hline
\end{tabular}


Table 6 Risk factor analysis of late complications on the two factors for types of surgeries in Type IVa cysts

\begin{tabular}{lllll}
\hline & Risk ratio & \multicolumn{2}{l}{$95 \%$ confidence limits } & $P$-value \\
\hline Late complications & 1.2109 & 0.5416 & 2.7073 & 0.804 \\
Long-term biliary function & 1.184 & 0.5022 & 2.7915 & 0.797 \\
\hline
\end{tabular}

Note: the clinical outcomes between two surgery methods (surgery I and II) for Type IVa cysts were compared

resection of the cysts. These data strengthen the importance of patent bile flow in the prevention of cancer in these patients. In contrast, patients who had their cysts radically removed could still develop cancer. However, due to the small number of cancer cases, we are not yet able perform a statistical analysis on this issue. We will continue to follow-up these patients, and hope to present significant data in the future.

Our study has limitations. It is a retrospective study, and the study was confined to a single institution. In addition, the follow-up time was not long enough to examine the impact of radical excision and proper bile flow on postoperative cancer occurrence.

\section{Conclusions}

We have provided substantial evidence showing that ensuring patent bile flow greatly improved the long-term postoperative outcomes in adult patients with bile duct cysts, particularly in those with Type Ic and IVa cysts, and when complete excision was unachievable. The establishment of proper bile flow, in some cases, exerted a greater impact on long-term outcomes than did complete excision. Thus, establishing proper bile flow can ensure good long-term outcomes in complicated cases of bile duct cysts and when complete excision is not feasible. The improved surgical treatment approach, if further substantiated, can be expected to widely benefit adult patients with bile duct cysts, decreasing the likelihood of reoperation, and reducing the incidence of late complications and malignancy. Nevertheless, it should be noted that complete excision has been an essential surgical approach for bile duct cyst patients, and should still be achieved whenever possible.

\section{Additional file}

Additional file 1: Table S1. Relationship of surgery types and clinical outcomes. Table S2. Recent complications. Table S3. Grading of recent complications. Table S4. oncological follow up. (DOCX $15 \mathrm{~kb}$ )

\begin{abstract}
Abbreviations
ALP: alkaline phosphatase; ALT: alanine aminotransferase; AST: aspartate aminotransferase; BDC: bile duct cyst; CC: choledochal cyst; GGT: gammaglutamyl transferase; WBC: white blood cell count
\end{abstract}

\section{Availability of data and materials}

The datasets used and/or analyzed during the current study available from the corresponding author on reasonable request.

\section{Author's contributions}

We declare that all the listed authors have participated actively in the study and all meet the requirements of the authorship, all authors have read and approved the manuscript. Dr. HTX, Dr. TY, Dr. YL and Dr. JHD designed the study, wrote the protocol and performed the operation; Dr. TY, Dr. YL, Dr. BL and Dr. JW assisted in the operation and collected the clinical data; Dr. HTX, Dr. TY and Dr. JW managed the literature searches and analyses; Dr. HTX and Dr. YL undertook the statistical analysis; Dr. HTX and Dr. TY wrote the first draft of the manuscript.

\section{Ethics approval and consent to participate}

The study was approved by the Institutional Review Board of the Chinese PLA General Hospital, and because of the retrospective nature of the study the requirement of informed consent was waived. All patients provided informed consent for the surgical procedures performed.

\section{Consent for publication}

Not Applicable.

\section{Competing interests}

Dr. HTX, Dr. TY, Dr. YL, Dr. BL, Dr. JW and Dr. JHD have no conflicts of interest or financial ties to disclose. The authors declare that they have no competing interests.

\section{Publisher's Note}

Springer Nature remains neutral with regard to jurisdictional claims in published maps and institutional affiliations.

Received: 11 February 2018 Accepted: 15 August 2018

Published online: 23 August 2018

\section{References}

1. Lipsett PA, Pitt HA, Colombani PM, Boitnott JK, Cameron JL. Choledochal cyst disease. A changing pattern of presentation. Ann Surg. 1994;220:644-52.

2. Lee SE, Jang JY, Lee YJ, Choi DW, Lee WJ, Cho BH, et al. Choledochal cyst and associated malignant tumors in adults: a multicenter survey in South Korea. Arch Surg. 2011;146:1178-84.

3. Shah OJ, Shera AH, Zargar SA, Shah P, Robbani I, Dhar S, et al. Choledochal cysts in children and adults with contrasting profiles: 11-year experience at a tertiary care center in kashmir. World J Surg. 2009;33:2403-11.

4. Soares KC, Arnaoutakis DJ, Kamel I, Rastegar N, Anders R, Maithel S, et al. Choledochal cysts: presentation, clinical differentiation, and management. J Am Coll Surg. 2014;219:1167-80.

5. Huang CS, Huang CC, Chen DF. Choledochal cysts: differences between pediatric and adult patients. J Gastrointest Surg. 2010;14:1105-10.

6. Cho MJ, Hwang S, Lee YJ, Kim KH, Ahn CS, Moon DB, et al. Surgical experience of 204 cases of adult choledochal cyst disease over 14 years. World J Surg. 2011:35:1094-102.

7. Bhavsar M, Vora H, Giriyappa V. Choledochal cysts : a review of literature. Saudi J Gastroenterol. 2012;18:230-6.

8. Xia HT, Dong JH, Yang T, Liang B, Zeng JP. Selection of the surgical approach for reoperation of adult choledochal cysts. J Gastrointest Surg. 2015:19:290-7.

9. Xia HT, Yang T, Liang B, Zeng JP, Dong JH. Treatment and outcomes of adults with remnant intrapancreatic choledochal cysts. Surgery. 2016;159:418-25.

10. Atkinson HDE, Fischer CP, de Jong CHC, Madhavan KK, Parks RW, Garden OJ. Choledochal cysts in adults and their complications. HPB : The Official Journal of the International Hepato Pancreato Biliary Association. 2003;5:105-10.

11. Soares KC, Kim Y, Spolverato G, Maithel S, Bauer TW, Marques H, et al. Presentation and clinical outcomes of choledochal cysts in children and adults: a multi-institutional analysis. JAMA Surg. 2015;150:577-84.

12. Sastry AV, Abbadessa B, Wayne MG, Steele JG, Cooperman AM. What is the incidence of biliary carcinoma in choledochal cysts, when do they develop, and how should it affect management? World J Surg. 2015;39:487-92.

13. Chaudhary A, Dhar P, Sachdev A. Reoperative surgery for choledochal cysts. Br J Surg. 1997:84:781-4

14. Ohashi T, Wakai T, Kubota M, Matsuda Y, Arai Y, Ohyama T, et al. Risk of subsequent biliary malignancy in patients undergoing cyst excision for congenital choledochal cysts. J Gastroenterol Hepatol. 2013;28:243-7. 
15. Xia HT, Yang T, Liang B, Zeng JP, Dong JH. Role of the surgical method in development of postoperative cholangiocarcinoma in todani type iv bile duct cysts. Gastroenterol Res Pract. 2015;2015:417685.

16. Popova-Jovanovska R, Genadieva-Dimitrova M, Trajkovska M, Serafimoski V. Choledochal cysts: diagnosis and treatment. Prilozi. 2012;33:49-63.

17. Komi N, Tamura T, Miyoshi Y, Kunitomo K, Udaka H, Takehara H. Nationwide survey of cases of choledochal cyst. Analysis of coexistent anomalies, complications and surgical treatment in 645 cases. Surg Gastroenterol. 1984;3:69-73.

18. Todani T, Watanabe Y, Toki A, Urushihara N. Carcinoma related to choledochal cysts with internal drainage operations. Surg Gynecol Obstet. 1987;164:61-4

19. Singham J, Yoshida EM, Scudamore CH. Choledochal cysts. Part 3 of 3: management. Can J Surg. 2010;53:51-6.

20. Khandelwal C, Anand U, Kumar B, Priyadarshi RN. Diagnosis and management of choledochal cysts. Indian J Surg. 2012;74:401-6.

21. Lenriot JP, Gigot JF, Segol P, Fagniez PL, Fingerhut A, Adloff M. Bile duct cysts in adults: a multi-institutional retrospective study. French associations for surgical research Ann Surg. 1998;228:159-66.

22. Moraca RJ, Lee FT, Ryan JA Jr, Traverso LW. Long-term biliary function after reconstruction of major bile duct injuries with hepaticoduodenostomy or hepaticojejunostomy. Arch Surg. 2002;137:889-93. discussion 893-884

23. Lillemoe KD, Melton GB, Cameron JL, Pitt HA, Campbell KA, Talamini MA, et al. Postoperative bile duct strictures: management and outcome in the 1990s. Ann Surg. 2000;232:430-41.

24. Xia HT, Dong JH, Yang T, Zeng JP, Liang B. Extrahepatic cyst excision and partial hepatectomy for todani type iv-a cysts. Dig Liver Dis. 2014;46:1025-30

25. Xia HT, Liang B, Liu Y, Yang T, Zeng JP, Dong JH. Ultrathin choledochoscope improves outcomes in the treatment of gallstones and suspected choledocholithiasis. Expert Rev Gastroenterol Hepatol. 2016;10:1409-13.

26. Xia HT, Wang J, Yang T, Liang B, Zeng JP, Dong JH. Sphincter of oddi dysfunction and the formation of adult choledochal cyst following cholecystectomy: a retrospective cohort study. Medicine (Baltimore). 2015;94:e2088.

27. Todani T, Watanabe Y, Toki A, Morotomi Y. Classification of congenital biliary cystic disease: special reference to type ic and Iva cysts with primary ductal stricture. J Hepato-Biliary-Pancreat Surg. 2003:10:340-4.

28. Todani T, Watanabe Y, Toki A, Ogura K, Wang ZQ. Co-existing biliary anomalies and anatomical variants in choledochal cyst. Br J Surg. 1998;85:760-3.

29. Kamisawa T, Okamoto A, Tsuruta K, Tu Y, Egawa N. Carcinoma arising in congenital choledochal cysts. Hepato-Gastroenterology. 2008:55:329-32.

30. He XD, Wang L, Liu W, Liu Q, Qu Q, Li BL, et al. The risk of carcinogenesis in congenital choledochal cyst patients: an analysis of 214 cases. Ann Hepatol. 2014;13:819-26.

31. Lee K, Tam YH, Chan EKW, Sihoe J, Cheung GST, Mou J. A Twenty-year Experience in Choledochal Cysts in Children: From Open to Laparoscopic Excision, vol. 14; 2009.

32. Kamisawa T, Kuruma S, Tabata T, Chiba K, Iwasaki S, Koizumi S, Kurata M, Honda G, Itoi T. Pancreaticobiliary maljunction and biliary cancer. Gastroenterology. 2015:50(3):273-9.

33. Kim JW, Moon SH, Park DH, Lee SS, Seo DW, Kim MH, Lee SK. Course of choledochal cysts according to the type of treatment. Scand J Gastroenterol. 2010;45(6):739-45.

Ready to submit your research? Choose BMC and benefit from:

- fast, convenient online submission

- thorough peer review by experienced researchers in your field

- rapid publication on acceptance

- support for research data, including large and complex data types

- gold Open Access which fosters wider collaboration and increased citations

- maximum visibility for your research: over $100 \mathrm{M}$ website views per year

At $\mathrm{BMC}$, research is always in progress.

Learn more biomedcentral.com/submissions 